\title{
Interfaces entre o ensino de ciências e a sociologia ambiental na formação de educadores do campo
}

\section{Interfaces between science teaching and environmental sociology in the training of field educators}

\author{
Andréia Sangalli (andreiasangalli@ufgd.edu.br) \\ Universidade Federal da Grande Dourados (UFGD) \\ Jeanne Mariel Brito de Moura Maciel (jeannemoura@ufgd.edu.br) \\ Universidade Federal da Grande Dourados (UFGD)
}

Resumo: Os debates sobre práticas de ensino e aprendizagem em ciências têm sido direcionados, fundamentalmente, na formação de professores para a área de ciências da natureza. Mas, ao considerar a singularidade da formação de professores para a educação do/no campo, é fulcral ampliar os horizontes desse debate compreendendo que as dimensões da ciência envolvem os sujeitos, seus territórios e as múltiplas interações que ali ocorrem. Nessa perspectiva, o presente trabalho discute a situação atual das políticas públicas acessadas pelas famílias assentadas da reforma agrária, bem como indígenas, a organização e gestão da produção de alimentos nesses espaços do estado de Mato Grosso do Sul e a vinculação desses fatores com a educação do campo. A pesquisa ocorreu em dois momentos distintos, porém conectados, relacionados com a própria organização do curso de Licenciatura em Educação do Campo. No tempo universidade foram adotadas como estratégias metodológicas: oficinas de diálogos sobre a dinâmica socioambiental das reservas indígenas e assentamentos alvo da pesquisa, e a utilização de questionário online na Plataforma Google forms, aplicado em tempo real. No tempo comunidade, utilizou-se de Pesquisa/Intervenção na comunidade através de entrevistas realizadas pelos estudantes com os assentados, representantes indígenas e lideranças de associações produtivas. Através da realização da pesquisa foi possível vislumbrar a importância de incluir as dimensões socioambientais e produtivas às práticas de ensino na formação de professores, bem como nas escolas de educação básica, visto que ensinar é, antes de tudo, ter a capacidade de relacionar as práticas de vida dos educandos ao processo de aprendizagem.

Palavras-chave: educação do campo; territórios camponeses e indígena; realidade socioambiental e cultural; ensino de ciências.

Abstract: The debates on teaching and learning practices in science have been directed, fundamentally, in the training of teachers for the area of natural sciences. However, when considering the singularity of teacher training for field education, it is crucial to broaden the horizons of this debate, understanding that the dimensions of science involve the subjects, their territories and the multiple interactions that occur there. In this perspective, this paper discusses the current situation of public policies accessed by settled families from agrarian reform, as well as indigenous peoples, the organization and management of food production in these spaces in the state of Mato Grosso do Sul and the link of these factors with the field education. The research took place in two distinct, yet connected moments, related to the organization of the Degree in Field 
Education. At the time of university, methodological strategies were adopted: dialogue workshops on the socio-environmental dynamics of indigenous reserves and settlements targeted by the research, and the use of an online questionnaire on the Google Forms Platform, applied in real time. In community time, Research / Intervention in the community was used through interviews conducted by students with settlers, indigenous representatives and leaders of productive associations. Through the research it was possible to glimpse the importance of including the socio-environmental and productive dimensions to teaching practices in teacher training, as well as in basic education schools, since teaching is, above all, having the ability to relate practices of life of the students to the learning process.

Keywords: field education; peasant and indigenous territories; socio-environmental and cultural reality; science teaching.

\section{INTRODUÇÃO}

A formação de educadores do campo tem se constituído em um palco de amplas discussões acerca das relações entre o cotidiano da vida camponesa e a práxis pedagógica no ensino formal. Nesse palco, inúmeros desafios têm sido enfrentados para a consolidação de um modelo de educação que adentre as ciências presentes nos territórios, nas tecnologias, nas práticas e culturas de vida de seus atores.

Os enredos do espetáculo se ampliam quando no palco há atores que trazem consigo experiências próprias e únicas, mas que só através do contracenar possibilitam a partilha e a concretização de novas experiências e saberes. No palco em questão, estão atores camponeses e indígenas e o cenário envolve o diálogo entre territórios distintos, mas que defendem o mesmo direito: a alimentação, a saúde, a educação, a autonomia de poder viver e trabalhar a terra em espaços que reafirmem suas identidades e suas culturas.

Esse palco traz à tona uma discussão que deve ser fundamentada e ampliada: de que forma se tem estruturado a relação dos camponesas e indígenas com os recursos bióticos e abióticos para o exercício das práticas produtivas (trabalhar na terra e produzir alimentos)? Que políticas públicas estão acessíveis a esses territórios para contribuir com o desempenho dessas atividades? E como a ciência imbuída nessas práticas podem ser incorporadas nos processos de ensino e formação de educadores?

A possibilidade de buscar respaldo a esses questionamentos foi vislumbrada durante a execução da disciplina Organização e Gestão da Produção no Campo, que 
compõe o rol de componentes curriculares para a formação de educadores do campo nas áreas de Ciências da Natureza e Ciências Humanas pela Faculdade Intercultural Indígena na Universidade Federal da Grande Dourados (UFGD).

Ao considerar a singularidade do curso, que reúne estudantes camponeses e indígenas, há um vasto campo territorial a transitar, e consequentemente ampliam-se os desafios em identificar estratégias de ensino que efetivem o fazer docente e uma formação docente engajada à rotina de vida camponesa. Por essas prerrogativas, um dos caminhos possíveis foi estabelecer as interfaces e inter-relações entre o ensino de ciências e a sociologia ambiental através da análise sobre os desenhos atuais de organização e gestão dos recursos naturais nas aldeias e assentamentos de Mato Grosso do Sul (MS) e das construções sociais que possibilitam condições de viver e permanecer nesses territórios.

Como aponta Martins e Madureira (2019),

No mundo rural, a diversidade resultante destas construções afeta decisivamente o gerenciamento das relações interpessoais e os tipos de controle e luta classificatória que os atores podem produzir sobre o próprio ambiente natural (p.329). O desafio reside na apreensão das práticas sociais profundamente enraizadas na interação sociedade-ambiente, que demandam novos esforços de compreensão do uso capitalista dos recursos territoriais, para além da tradicional exploração agrícola dos ecossistemas rurais (p. 337).

Assim, tem-se que a educação não se constitui como um ato fantasmagórico, e externo aos agentes, mas como uma ação que parte do concreto, das experiências da vida cotidiana daqueles que partilham da comunidade escolar: estudantes, professores, gestores e a unidade familiar. No caso em questão, é o próprio mundo rural e suas contingências que informam o universo do ensino e da aprendizagem.

Portanto, ignorar as nuances sociais e a diversidade de fatores que fazem parte do percurso formativo dos estudantes possibilita, de certa forma, a legitimação de uma “cultura dominante", como diria Bourdieu e Passeron (2014), que não se tenta as demandas em que os sujeitos educandos estão inseridos. E, mais do que isso, contribui desse modo, "para reproduzir a estrutura das relações de força, numa formação social onde o sistema de ensino dominante tende a assegurar-se do monopólio da violência simbólica legítima" (BOURDIEU; PASSERON, 2014, p. 27). 
$\mathrm{Na}$ tentativa de romper com esses pressupostos, a educação do campo, enquanto campo do saber e fruto da reivindicação dos movimentos sociais campesinos, se concretiza sob os pressupostos de uma educação transformadora, interdisciplinar e que dialoga com o lugar, as pessoas e as condições econômicas e ambientais que as informam.

A educação do campo é uma educação que foi pensada em benefício dos jovens camponeses, é uma educação própria para o campo e que respeita o seu tempo, sua relação socioespacial, as relações de circunvizinhança, a cultura e seus modos de viver no território. Jamais como uma educação que se sobrepõem sobre os processos locais.

Isso revela que o intuito da educação do campo é a preparação para as gerações que nascem no campo. Ou seja, a educação do campo é aquela que busca pensar a educação dos camponeses atrelado a luta de classes, visto que há uma tensa relação que envolve o camponês e a sociedade urbano-industrial, que historicamente marginalizou os seus modos de ver e de estar no mundo. Portanto, a educação na perspectiva camponesa é como um esporte de combate à tentativa de uma pressuposta universalização do conhecimento. Além disso, é uma educação que busca ser libertadora da subordinação do meio rural ao capital, ao agronegócio (CALDART, 2012).

A educação do campo é um fenômeno da realidade brasileira atual, que nasceu no final da década de 1990, a partir das demandas dos trabalhadores do campo e suas organizações na busca por uma política educacional que atendesse aos interesses dos camponeses, superando a história de desigualdades de acesso à educação (MOLINA, 2006, p. 90).

De acordo com Caldart (2016, p. 91) a Educação do campo possui 4 vertentes em sua concepção:

$\left(1^{\circ}\right)$ não tem como pensar/fazer a Educação do Campo fora ou sem considerar a contradição fundamental entre capital e trabalho e, pela nossa opção de classe, sem o objetivo de superação das leis fundamentais de funcionamento da lógica de produção que move o capitalismo: exploração do trabalho e exploração da natureza; $\left(2^{\circ}\right)$ que não tem como educar sem dar centralidade às condições de existência social em que cada ser humano se forma: a produção da existência e a formação do ser humano são inseparáveis; as pessoas se formam pela inserção em um determinado meio, sua materialidade, cultura, natureza e sociedade e nele, nos processos de produção material da existência; por isso não podemos pensar o destino da 
educação fora do destino histórico do trabalho; $\left(3^{\circ}\right)$ que não tem como pensar a Educação do Campo (e a educação dos camponeses, por suposto) apenas como educação escolar e nem deixar de dar centralidade à escola, em nossas lutas e esforços de construção; $\left(4^{\circ}\right)$ e não tem como na educação deixar de dar centralidade ao debate sobre conhecimento, em uma concepção que o vincula ao conjunto dos processos formativos do ser humano e visando uma interpretação da realidade que permita ao ser humano transformá-la.

Portanto, na concepção de Caldart, não se pode pensar em educação dos camponeses sem uma reflexão do modo de produção capitalista, visto que a educação é uma expressão da sociedade burguesa e de suas bases de produção econômica, voltada, sobretudo, para atender os interesses das elites dominantes e para formar uma classe trabalhadora não-emancipada, mas subordinada ao modo de produção urbano-industrial.

Assim, tem-se que a educação do campo reivindica uma educação do e no campo, atrelada as subjetividades concretas e simbólicas que permeiam esse rural:

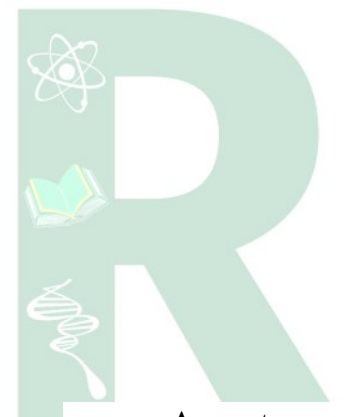

A Educação do Campo tem como sujeitos concretos todos os trabalhadores do campo, em sua diversidade, mas sua base de concepção se vincula aos camponeses, ao trabalho e ao modo de vida camponês, também na diversidade que os constitui. Não se pode pensar a Educação do Campo sem pensar a educação dos camponeses porque a base da Educação do Campo está no trabalho camponês, familiar e associado, e no desafio de ajudar no seu fortalecimento, mesmo sob as ameaças constantes e cada vez mais fortes de sua destruição pelo capital (CALDART, 2016, p. 92)

A autora aponta, ainda, que agricultores familiares, quilombolas, sem terras, indígenas, mestiços, agricultores urbanos e rurais, são sujeitos que buscam afirmar seus pertencimentos sociais como "povos do campo" e, por isso mesmo, demandam uma educação que respeite as suas singularidades. A educação do campo, dessa forma, seria a única capaz de atender às suas demandas.

No que concerne ao arcabouço da Legislação vigente, que ampara a presente discussão, destaca-se os Marcos Normativos para a Educação do Campo, que em seu Art. $2^{\circ}$ apresenta os princípios da educação do campo:

I - respeito à diversidade do campo em seus aspectos sociais, culturais, ambientais, políticos, econômicos, de gênero, geracional e de raça e etnia; II ...articulação de experiências e estudos direcionados para o desenvolvimento social, economicamente justo e ambientalmente sustentável, em articulação com o mundo do trabalho; III - desenvolvimento de políticas de formação de profissionais da educação para o atendimento da especificidade das escolas do campo, considerando-se as condições concretas da produção e reprodução social da vida no campo; ...(BRASIL 2012a, p. 82). 
No intuito de fazer essa conexão da educação do campo com o mundo do trabalho e o meio ambiente, a Resolução $N^{0}$ 2, de 15 de junho de 2012, que estabelece as Diretrizes Curriculares Nacionais para a Educação Ambiental, foi central para o amparo institucional das práticas interdisciplinares e multiterritorial da educação do campo. A normativa dispõe que:

Art. $2^{\circ}$ A Educação Ambiental é uma dimensão da educação, é atividade intencional da prática social, que deve imprimir ao desenvolvimento individual um caráter social em sua relação com a natureza e com os outros seres humanos, visando potencializar essa atividade humana com a finalidade de torná-la plena de prática social e de ética ambiental.

Art. $3^{\circ}$ A Educação Ambiental visa à construção de conhecimentos, ao desenvolvimento de habilidades, atitudes e valores sociais, ao cuidado com a comunidade de vida, a justiça e a equidade socioambiental, e a proteção do meio ambiente natural e construído.

Art. $6^{\circ}$ A Educação Ambiental deve adotar uma abordagem que considere a interface entre a natureza, a sociocultura, a produção, o trabalho, o consumo, superando a visão despolitizada, acrítica, ingênua e naturalista ainda muito presente na prática pedagógica das instituições de ensino (BRASIL, 2012b, p. 2).

Nesse sentido, a resolução da educação ambiental como um eixo central e obrigatório na formação de professores nos anos 2000, bem como a efetivação de políticas públicas específicas para o meio rural em finais dos anos 1990, se tornaram, em grande medida, uma base sólida da integração de saberes e contextos na formação de educadores do campo. Dentre as políticas públicas rurais, o Programa Nacional de Fortalecimento da Agricultura (PRONAF), instituído através do Decreto Presidencial nº 1.946 de 28 de junho de 1996, foi a principal política pública governamental para o campo tendo por finalidade promover o desenvolvimento sustentável do segmento rural constituído pelos agricultores familiares, de modo a propiciar-lhes o aumento da capacidade produtiva, a geração de empregos e a melhoria de renda (Art. $1^{\circ}$ ) $($ BRASIL, 1996).

Assim, a sociologia, e mais especificamente a sociologia ambiental, foi acionada como ferramenta de análise, juntamente com a área do ensino de ciências, na compreensão do território indígena e dos assentamentos rurais do MS como produtores de saber e de cultura na perspectiva da educação do campo. Assim como o ensino de ciências parte da perspectiva de uma agenda de pesquisa que vincula o ensino às dimensões dos fenômenos físicos e biológicos que rodeiam a sociedade, a sociologia 
ambiental também chama para si a tarefa de relacionar a sociedade - enquanto espaço complexo de realização do agir humano - à dimensão ambiental e aos modos de produção específicos do mundo rural.

Sobre esse aspecto, Martins e Cunha (2020, p.1) apontam que,

\begin{abstract}
Se as modernas sociedades industriais são marcadas por um intensivo processo de artificialização da vida social, produzindo crescente desconexão das atividades cotidianas em relação ao mundo natural (que é recriado incessantemente pela ação antrópica), é no meio rural que as contradições inerentes a esse processo se mostram de forma mais aguda, dado que os entrelaçamentos entre dinâmicas das atividades produtivas praticadas nesses espaços e os ciclos da natureza são mais diretamente percebidos e tomados como problemáticos. Apesar disso, foi apenas a partir da década de 1970, em meio à emergência de uma questão ambiental global, que as articulações entre ruralidades e meio ambiente passaram a ter maior centralidade no campo dos chamados estudos rurais. Estudos realizados em diferentes contextos nacionais, amparados em uma gama variada de matrizes teóricas e disciplinares, revelaram os profundos impactos sociais e ambientais decorrentes da chamada modernização da agricultura promovida pela revolução verde (...).
\end{abstract}

Conforme ressaltado acima, é a partir da década de 1970 que os estudos sociológicos se debruçam sobre os impactos ambientais das ações dos seres humanos nos agrupamentos sociais e, principalmente, no mundo rural e no mundo de trabalho rural. Assim, as pesquisas ambientais na área da sociologia vão dar conta de diversas problemáticas, como "ambientalização dos conflitos agrários", "recursos comuns", "políticas ambientais", "agricultura familiar", "unidades de conservação", "crise hídrica", dentre outros (MARTINS; CUNHA, 2020). Somado a isso, a sociologia também vai se apropriar da análise da educação ambiental nas escolas, enquanto eixo de saber, e das interpelações possíveis com as demais áreas do conhecimento.

Respaldando-se nos preceitos acima elencados, o presente trabalho discute a situação atual das políticas públicas acessadas pelas famílias assentadas e indígenas, os desenhos atuais de organização e gestão da produção de alimentos nos assentamentos e aldeias de Mato Grosso do Sul, bem como de que forma a escassez ou abundância de recursos naturais têm influenciado na organização sociocultural desses territórios, e a vinculação desses fatores com a educação do campo.

A compreensão dessas realidades é fulcral ao educador camponês, para que os diálogos propiciem transformar os óbices sociais e as múltiplas ciências utilizadas cotidianamente, a fim de superá-los com a efetivação de conteúdos de aprendizagem e 
de valoração da vida humana e do ambiente que correspondam a realidade em que os estudantes das escolas do campo estão inseridos:

Atribuir aos atores locais a condição de sujeitos nos processos que incidem sobre o seu mundo e suas vidas faz com que a transformação da realidade local ocorra a partir da valorização de fenômenos decorrentes de um processo histórico de evolução entre uma sociedade específica e seu ecossistema (HEBERLÊ et al, 2017, p. 140)

\section{PROCESSOS METODOLÓGICOS}

Dentre os objetivos de trabalhar políticas públicas de desenvolvimento territorial na formação de professores da educação do campo, estão o de: a) oportunizar aos estudantes o acesso aos estudos teóricos e de aprofundamento dos modelos de Políticas Públicas para o campo no Brasil; b) atualizar os conhecimentos sobre as atuais Políticas para as comunidades camponesas; c) ampliar os contatos com experiências de associativismo, cooperativismo e sócio economia solidária; d) aprofundar os conhecimentos em agroecologia como um sistema integrativo e que favorece otimização dos espaços e recursos disponíveis a curto, médio e longo prazo; e) compreender o estado da arte da organização e gestão dos assentamentos de MS; f) vislumbrar alternativas que possibilitem a melhoria na gestão dos recursos para a permanência das famílias no campo e g) identificar os elos possíveis entre produção, gestão e educação escolar camponesa.

Dito isso, os procedimentos da pesquisa ocorreram em dois momentos distintos, porém conectados, que se relacionam com a própria organização do curso de Licenciatura em Educação do Campo, que são o tempo universidade - em que os estudantes ficam por um período de 15 dias em alojamento da UFGD para ter aulas - e o tempo comunidade - caracterizado pelo retorno dos discentes às suas comunidades a fim de desenvolverem o cronograma de pesquisa estipulado pelo professor/professora.

$\mathrm{Na}$ primeira etapa, identificada como Tempo Universidade, o processo de construção do conhecimento pautou-se inicialmente em diagnosticar a situação atual das políticas públicas acessadas pelas famílias assentadas e indígenas representadas, naquele momento, pelos estudantes matriculados na disciplina. Nessa fase, foram adotadas duas estratégias metodológicas: a realização de oficinas de diálogos sobre a dinâmica socioambiental das reservas indígenas e assentamentos alvo da pesquisa, e a utilização 
de um questionário elaborado na Plataforma Google forms e aplicado em tempo real. Além de temas trabalhados em sala de aula, mas que não são o foco da presente pesquisa.

Na segunda etapa, denominada de tempo comunidade - e relacionada a atividade de Pesquisa/Intervenção na comunidade - utilizou-se de entrevistas guiadas pelas docentes e realizadas pelos estudantes com os assentados, representantes indígenas e lideranças de associações produtivas, com o foco central dos questionamentos em saber: como tem sido o acesso da comunidade aos Programas de desenvolvimento para o campo, como ocorre a participação de organizações locais na intermediação de acesso às políticas públicas, qual o nível de acesso ao PRONAF, Programa de Aquisição de Alimentos (PAA), como está organizada as cadeias produtivas e os arranjos produtivos locais, e, por fim, como se dá a presença de associações e cooperativas nesses territórios.

Sobre o lugar da pesquisa, os dados foram obtidos nos municípios de Sidrolândia, Ponta Porã, Itaquiraí, Corumbá, Ladário, Nioaque, Dourados, Douradina e Laguna Caarapã, com a representatividade de municípios de todas as divisões territoriais do estado.

Posto isso, segue abaixo o detalhamento dos principais resultados da pesquisa e da sua relação com esses múltiplos territórios analisados no MS. Ressalta-se que ao término das transcrições dos interlocutores, utilizou-se como identificação o nome de espécies vegetais do Cerrado e Pantanal sul mato-grossense que fazem parte da composição da sociobiodiversidade local (Araçá - Psidium guinnensis Sw.; Baru Dipteryx alata Vog.; Guavira- Campomanesia adamantium (Cambess.) O. Berg; Jatobá do cerrado -Hymenaea stigonocarpa Mart.ex Hayne; Pequi - Caryocar brasiliense Camb.), reiterando a importância das relações socioecológicas entre seres humanos e natureza.

\section{RESULTADOS}

\subsection{Os múltiplos territórios em MS e a representatividade em sala de aula}

Com 357.145,532 km2 e 2.449.024 habitantes (IBGE, 2014), o estado de Mato Grosso do Sul tem sua essência marcada pela diversidade populacional e cultural constituindo-se como espaço multiterritorial. Em 29 municípios estão distribuídas 83 
Terras Indígenas (TIs) e uma população indígena de 80.459 habitantes (SECID/MS, 2020).

\begin{abstract}
Os povos indígenas atualmente assentados em Mato Grosso do Sul são onze: Terena e Kinikinau, ambos da família linguística arawak; Kaiowa e Guarani, da família linguística tupi-guarani; Kadiwéu, de língua guaikurú; Ofaié (também conhecidos como Ofaié-Xavante) e Guató, do tronco macrojê; Chamacoco e Ayoreo de língua zamuco; Atikum e Camba, cada um com uma língua original isolada, que hoje não falam mais (CHAMORRO; COMBÈS, 2015 , p. 20).
\end{abstract}

Quanto aos Projetos de Assentamento (PAs), no estado há 204 assentamentos, e 27.764 famílias assentadas, dispersas em um território de mais de 700 mil hectares (INCRA, 2020).

Os 25 estudantes participantes da pesquisa compõem uma representatividade desses múltiplos territórios sendo oriundos de 17 Projetos de Assentamentos- PA. No município de Sidrolândia: PA Eldorado, PA Eldorado 1, PA Eldorado 2 e PA São Pedro; Em Ponta Porã: PA Itamarati Sede, PA Itamarati I e PA Itamarati II; Em Itaquirai: PA Guassu, PA Tamakavi, PA Santo Antônio e PA Santa Rosa; Em Corumbá: PA Tamarineiro I e PA Taquaral; Em Ladário: PA Alta Floresta I; Em Nioaque: PA Andalucia, Em Bela Vista- PA Caracol e em Terenos: PA Santa Mônica. E de 4 Terras Indígenas (TI): TI Jaguapiru e TI Panambizinho, em Dourados; TI Lagoa Rica, em Douradina; TI Rancho Jacaré, em Laguna Caarapã.

Esses múltiplos territórios são espaços plurais em relação às características geográficas, populacionais, econômicas e ambientais, realçando as inter-relações entre as "sócio-logias" dos ambientes e as ciências implícitas e explícitas nessas relações.

\begin{abstract}
A concepção de território, em sua versão mais simples, refere-se às dimensões jurídica e administrativa de áreas geograficamente delimitadas. Nessa perspectiva, o território está relacionado aos processos de controle, de dominação e/ou de apropriação dos espaços físicos por agentes públicos e privados. Ele pode ser transformado por meio de práticas e significações dos espaços ocupados pelas comunidades. A esfera social da territorialidade corresponde, em certa medida, à reprodução de uma formação socioeconômica concretizada em relações de trabalho, na produção, na distribuição, na troca e no consumo de bens e serviços em um mercado regional (NETO; PENHA, 2017, p. 207).
\end{abstract}

Outro aspecto que contribui para a ampla diversidade cultural sul mato-grossense, são as extensas dimensões de fronteiras com outros países. Assim, dentre os municípios 
fronteiriços destacam-se Ponta Porã - fronteira Brasil/Paraguai, sendo cidade gêmea ${ }^{1}$ com Pedro Juan Caballero, e o município de Corumbá - fronteira tríplice entre Brasil/Paraguai/Bolívia, que apresenta a condição de cidade gêmea em relação à cidade boliviana de Puerto Quijarro (HIGA; ANZAI; GATTI, 2017).

Mato Grosso do Sul conta com 44 municípios fronteiriços, dos quais três estão na faixa de fronteira com a Bolívia: Corumbá, Aquidauana e Miranda. Os demais, no total de 41, estão na faixa com o Paraguai. Entre estes 44 municípios da faixa de fronteira, doze têm seus territórios dispostos ao longo da linha limítrofe internacional: Corumbá, Porto Murtinho, Caracol, Bela Vista, Antônio João, Ponta Porã, Aral Moreira, Coronel Sapucaia, Paranhos, Sete Quedas, Japorã e Mundo Novo (Idem, p. 31).

Como aponta Neto e Penha (2017), as fronteiras internacionais são espaços sociais de interação, em que "o convívio transfronteiriço, é bastante complexo e não se restringe aos seus aspectos econômicos e aduaneiros, na medida em que também corresponde à esfera da vida cotidiana e estende-se àquilo que diz respeito às relações interpessoais" (p. 207). E condicionadas a outras estruturas para além das sociais, essas relações interpessoais configuram-se também em relações ambientais, que se ampliam diante da diversidade biológica existente no Estado de MS, no qual concentra os Biomas Cerrado, Pantanal e Mata Atlântica.

Mato Grosso do Sul encontra-se numa região estratégica em termos de biodiversidade, onde ocorre o contato entre vários macroecossistemas: Cerrado, Chaco, Floresta Chiquitana, Floresta Atlântica, Floresta Amazônica. Cerradão é a fitofisionomia mais comum no estado, enquanto que cerrado stricto sensu e cerrado arbustivo frequentemente ocorrem em terrenos rochosos ou mal drenados. Na parte sul ocorre a Floresta Atlântica de interior ou semidecidual, ou da bacia do Paraná-Paraguai. Florestas secas são encontradas em afloramentos calcários ou basálticos. Savanas inundáveis monodominantes são encontradas no Pantanal (FARINACCIO et al, 2018, p. 12).

Em relação a diversidade florística o Programa Biota MS, contabilizou, em 2009, 3.911 espécies que compõe a flora de MS, destacando-se o grupo das angiospermas com a maior diversidade sendo de 2.730 espécies (FARINACCIO et al, 2018). Quanto a diversidade faunística, foram contabilizadas 5.195 espécies de animais, sendo 3.756 espécies de invertebrados e 1.439 espécies de vertebrados pertencentes aos grupos

\footnotetext{
${ }^{1}$ Nota Explicativa: Cidades gêmeas são zonas de fronteira com um espaço de interação, uma paisagem específica, com espaço social transitivo, composto por diferenças oriundas da presença do limite internacional, e por fluxos e interações transfronteiriças. É produto de processos e interações econômicas, culturais e políticas, tanto espontâneas como promovidas, a zona de fronteira é o espaço de políticas públicas de integração e cooperação, espaço-exemplo das diferenças de expectativas e transações do local e do internacional (BRASIL, 2005, p. 21).
} 
taxonômicos dos peixes ósseos- 358 espécies, anfíbios- 97 espécies, répteis- 188 espécies, aves- 630 espécies e mamíferos - 166 espécies (GRACIOLLI et al, 2017).

Outro fator de grande relevância é que o estado de MS está localizado sobre o Sistema Aquífero Guarani (SAG) e concentra a maior extensão do aquífero em território sul mato-grossense sendo de 189.451,38 $\mathrm{km}^{2}$. O Sistema Aquífero Guarani é a unidade hidroestratigráfica mais importante da porção meridional do continente sul-americano e está associado ao conjunto de rochas sedimentares originadas da acumulação mecânica de partículas detríticas (SANTA CRUZ et al, 2009, p. 20). E, como afirmam os autores, a disponibilidade hídrica do aquífero para a utilização e o conhecimento da recarga efetiva e da quantidade de água que pode ser extraída da reserva permanente, durante determinado período, é fundamental para evitar danos ambientais irreversíveis.

Em suma, a biodiversidade e os recursos naturais estão diretamente relacionados às dimensões socioambientais, políticas, econômicas e educacionais e, portanto, tornase relevante compreender, a partir das interações sociais, compreender as representações dos fatores ambientais que foram mobilizadas recursivamente neste processo de ressignificação do espaço (MARTINS; MADUREIRA, 2019).

\subsection{Agricultura familiar, produção alimentar a reprodução social}

A agricultura familiar se instituiu em uma forma de produção e trabalho historicamente marginalizada no Brasil e os pequenos agricultores sempre estiveram às margens das ações do Estado brasileiro (GRISA; SCHNEIDER, 2015). Para redimir o descaso com os pequenos agricultores foi instituído oficialmente em 1996 o PRONAF sendo concebido com a finalidade de apoiar o desenvolvimento rural, tendo como fundamento o fortalecimento da agricultura familiar, como segmento gerador de emprego e renda (AQUINO; SCHNEIDER, 2015, p. 57).

É importante destacar que a partir dos apontamentos de Sabourin, Samper e Massardier (2015), os estudos nacionais evidenciam três principais tipos de políticas públicas relativas à agricultura familiar na América Latina, e que não se excluem entre si:

1) políticas agrícolas ou agrárias generalistas, que incluem a categoria agricultura familiar- orientadas para a modernização da agricultura, facilitando o acesso a recursos e financiamentos para aumentar a produção e a produtividade e incluem um grupo de agricultores familiares; 2) políticas 
específicas para a categoria da agricultura familiar- apoiar prioritariamente as unidades familiares inscritas em dinâmicas de modernização tecnológica e de especialização produtiva para mercados de commodities e que não atende certos tipos de agricultores familiares ou camponeses, sendo os que produzem para autoconsumo ou para mercados de proximidade, unidades pluriativas (renda agrícola não alcança 70-80\%), pescadores artesanais, extrativistas ou produtores das minorias etnicas, indígenas ou afrodescendentes; e 3) políticas temáticas ou intersetoriais e que comprometem indiretamente os agricultores familiares- considera finalidades não propriamente agrícolas (proteção do meio ambiente, segurança alimentar, combate à pobreza rural e as desigualdades, desenvolvimento territorial, economia solidaria e familiar) (p. 607-608).

Em se tratando dos assentamentos sul mato-grossenses, estes constituem espaços geográficos produtivos com foco na agricultura familiar. Em relação ao acesso à Programas para a agricultura familiar nos territórios camponeses, o PRONAF tem sido o mais acessado pelas famílias (Figura 1).
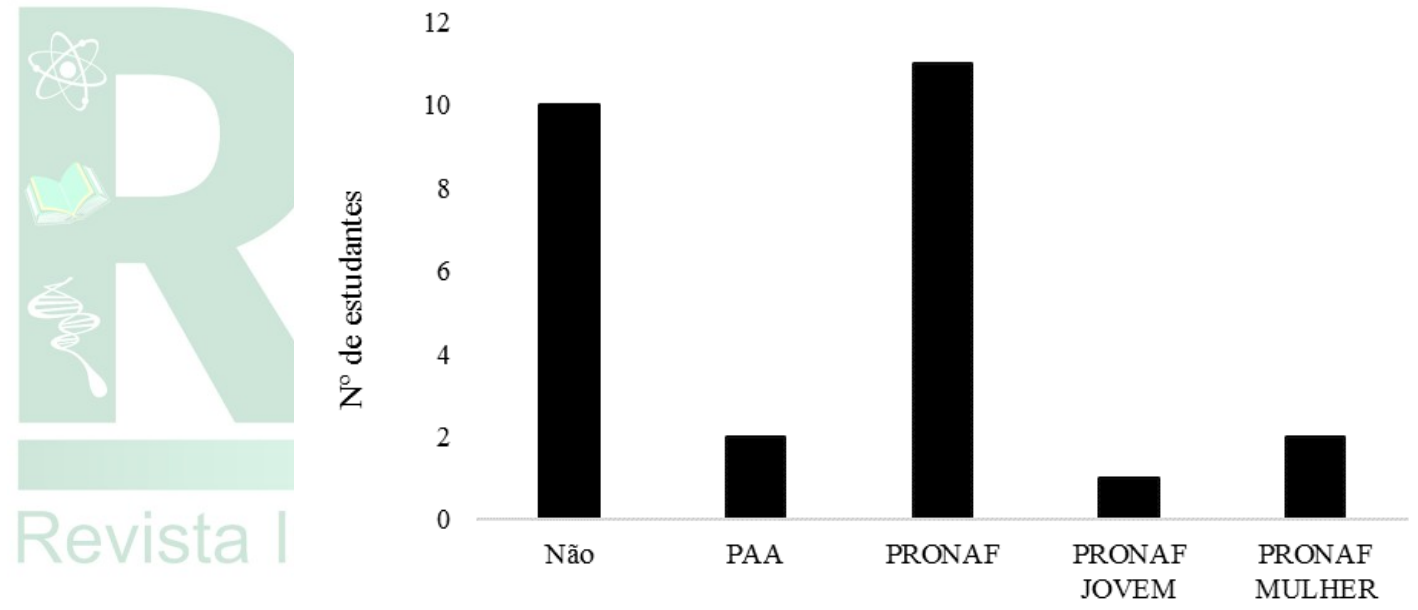

Acesso à Políticas Públicas

Figura 1. Acesso à Políticas Públicas para o desenvolvimento da agricultura familiar.

As principais dificuldades diagnosticadas no acesso aos programas de incentivo nos assentamentos em análise são: a regulamentação dos lotes a regulamentação dos lotes através da Declaração de Aptidão ao Pronaf - (DAP), as burocracias das instituições e agências bancárias e a falta de informações junto às famílias assentadas. Mas estas realidades diferem entre as regiões sul mato-grossense. Isso porque, constamos que os assentamentos rurais mais antigos e que receberam maior infraestrutura inicial, tiveram maior facilidade de acesso aos programas, quando comparados aos assentamentos recém reconhecidos e que ainda apresentam problemas com a regularização dos lotes (falta do DAP). 
política agrícola para a agricultura familiar - tanto em número de beneficiários, quanto em capilaridade nacional e recursos aplicados (p. 29). O reflexo da amplitude do programa é reafirmado no relato de uma das entrevistas camponesa:

\begin{abstract}
No Assentamento Itamarati, 90\% dos assentados já acessaram o Pronaf, com exceção dos segundos titulares. Há muitos que já acessaram custeio AC, e outros estão em linha de crédito que é o Mais Alimento; esta já é uma linha de crédito mais exigente, e o risco é maior. Mas em relação aos acessos iniciais, 90\% já acessaram (GUAVIRA).
\end{abstract}

Mas identificou-se a necessidade de ampliar as linhas de acesso ao Programa considerando principalmente a diversidade aquisitiva presente entre os camponeses, como destacam Grisa e Schneider (2015):

(...) logo após a institucionalização do Pronaf, as próprias organizações da agricultura familiar começaram a pautar a necessidade de o Pronaf atender a diversidade socioeconômica da agricultura familiar, culminando na criação de grupos e linhas direcionadas aos agricultores mais descapitalizados ou em situação de vulnerabilidade social (p. 33).

Derivando dessa ampliação, houve a diversificação de linhas de ação além do custeio e do investimento tradicionais sendo instituídos os PRONAFs: Agroindústria, Mulher, Jovem Rural, Semiárido, Floresta, Agroecologia, ECO Sustentabilidade Ambiental e o Mais Alimentos (MDA/SAF/PRONAF, 2013). Entretanto, o acesso a essas modalidades do programa apresentou-se muito limitado dentre os estudantes investigados e a principal justificativa da dificuldade de ingresso está na burocracia documental.

Outro programa que os camponeses sul mato-grossenses têm acessado é o PAA:

\begin{abstract}
Ele foi criado em 2003 visando articular a compra de produtos da agricultura familiar com ações de segurança alimentar (distribuição de Alimentos) para a população em vulnerabilidade social. E desencadeou uma nova trajetória para os mercados institucionais para a agricultura familiar, fortalecida em 2009 com a mudança no Programa Nacional de Alimentação Escolar (PNAE) e a criação da Lei no 11.947, que determinou que, no mínimo, 30\% dos recursos federais para a alimentação escolar sejam destinados para a aquisição de alimentos da categoria social (GRISA; SCHNEIDER, 2015, p. 39).
\end{abstract}

Enquanto o caráter do PRONAF seja o de acesso individual ou familiar, o acesso ao PAA depende, segundo os participantes da pesquisa, de estruturas sociais organizadas tais como associações ou cooperativas:

Em relação ao PAA, só acessam quem teria uma compreensão um pouco mais evoluída em relação ao cooperativismo, então quem quer acessar tem 
que se agarrar nas cooperativas, pois individualmente não se acessa. No assentamento hoje, umas 70 famílias estão acessando o PAA, mas já tivemos época em que 300 famílias acessavam. E tem entidades que não se organizam e não acessaram, e os produtores que entregavam antes não migraram para outras cooperativas. O PNAE só duas entidades estão operando, mas uma delas tem mais experiência. As entidades devem atender algumas exigências, como câmara fria, embalar produtos, os produtos vão com qualidade, e isso faz com que as cooperativas se desenvolvam (GUAVIRA).

Embora a realidade aqui apresentada refira-se a uma pequena parcela de camponeses, ela representa a realidade hodierna nos assentamentos, em que a existência de políticas públicas de incentivo à manutenção da cadeia alimentar permanece, em sua essência, na teoria, estando as possibilidades de execução ainda encrostadas de burocracias que impedem grande parte dos assentados de garantirem as mínimas condições de produzirem alimentos e permaneceram em suas terras.

O desafio no período recente consiste em possibilitar que o PAA se manifeste nas diversas realidades locais na mesma proporção da sua importância para o desenvolvimento rural, das reivindicações da sociedade civil, e de sua reputação política nacional e internacional. O Programa pode assumir um papel estruturante para a agricultura familiar e para a segurança alimentar e nutricional no país, para tanto e preciso fornecer condições orçamentarias e normativas (GRISA; PORTO, 2015, p. 176).

A falta de políticas adequadas para a agricultura familiar, com fins no sustento financeiro da unidade familiar e no seu autoconsumo, faz com que os povos camponeses, indígenas, quilombolas e outras comunidades tradicionais sejam vítimas de inúmeras dificuldades em garantir sua segurança alimentar e nutricional, apresentando maiores índices não só de insegurança alimentar como de desnutrição. Logo, esses grupos, historicamente detentores de conhecimentos ancestrais de cultivo de alimentos, mas sem terra e recursos (financeiros e/ou naturais), têm sérias limitações (ROCHA, 2015, p. 21).

Quanto às atividades e culturas produzidas nos lotes (Figura 2), constatou-se que a produção é voltada principalmente para o consumo familiar e que a comercialização se restringe ao leite, derivados lácteos, hortaliças e peixes. Segundo os estudantes, quando comercializados, o leite vai para os laticínios, mandioca para a fecularia, hortaliças para o PAA, PNAE (Programa Nacional de Alimentação Escolar) e quartel militar, e os derivados lácteos comercializados de porta em porta. 


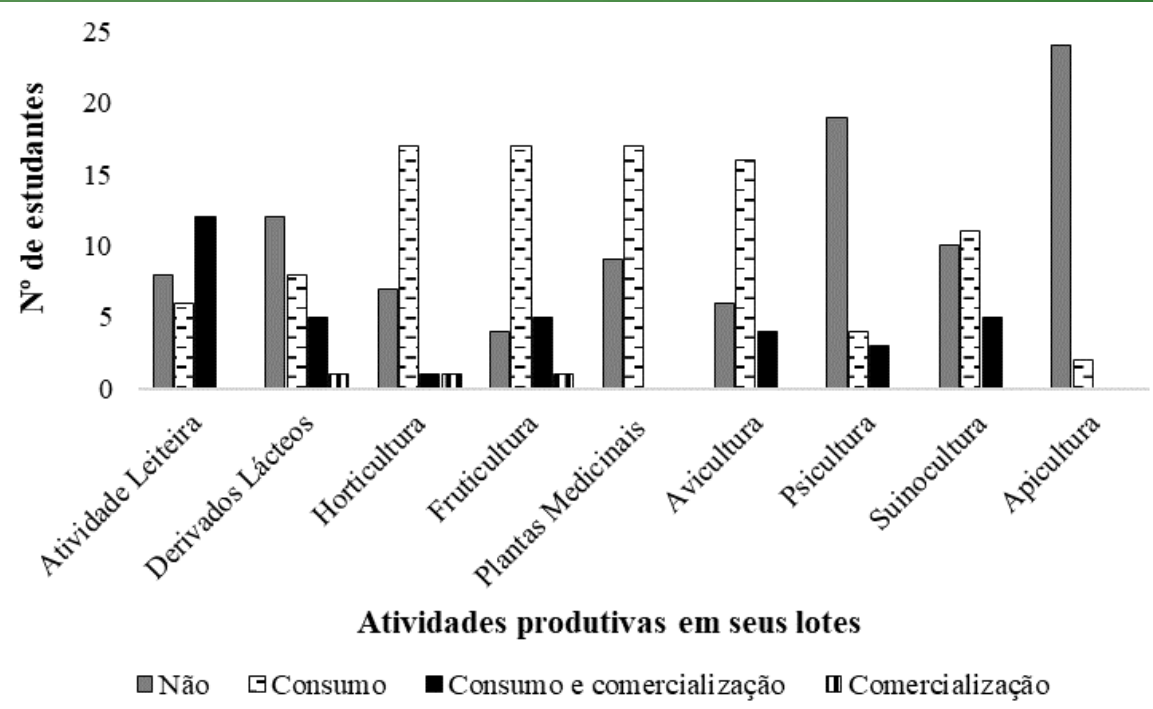

Figura 2. Atividades produtivas realizadas pelos estudantes e suas famílias em seus lotes.

A maior dificuldade apontada pelos estudantes envolvidos na realização da pesquisa não está na fase de produção, mas na fase de escoamento dos produtos pela dificuldade histórica de articulação das famílias com o acesso aos meios de transporte apropriados para o carregamento/deslocamento da produção, bem como pela falta de manutenção das estradas vicinais dos assentamentos pelos gestores municipais - sendo essa a realidade de muitos assentamentos de MS.

Ao longo dos municípios lindeiros (ou cidades gêmeas), a situação dos projetos de assentamentos é bastante diferenciada. Há assentamentos que contam com rodovias nas proximidades do projeto, o que facilita o acesso a mercados para a venda de sua produção; outros, que estão longe de mercados, contam com vias de acesso muito precárias. Muitos não dispõem de maquinários ou equipamentos que lhes permitam trabalhar melhor a terra e obter maior produtividade. Constatou-se, ainda, que alguns projetos de assentamento foram implantados em áreas secas, o que tem dificultado e até impossibilitado o sucesso destes empreendimentos (HIGA; ANZAI; GATTI, 2017, p.35).

Uma questão relevante que suscitou amplas discussões em sala de aula foi a questão da ação das associações e cooperativas quando presentes nos assentamentos. Nesse quesito, pode-se constatar que no início dos projetos as organizações funcionam bem e as decisões são tomadas coletivamente, mas com o passar do tempo surge um descompasso entre a gestão e os produtores associados. Há certo "abuso de poder" por parte de alguns presidentes de associações que incidem em dar prioridade ao uso de equipamentos e insumos para as famílias mais próximas. Quando as associações e cooperativas atuam através da gestão coletiva, outros cenários são possíveis: 
A associação do assentamento Tamakavi é bem organizada, no município é a única associação que tem todos equipamento agrícolas como (trator, colheitadeira entre outros), além disso, já tem projeto para um grande barracão para guardar todos esses equipamentos, mas mesmo tendo todo o material para a construção eles afirmam que há muita burocracia para associações. Segundo o presidente da associação, a quantidade de pessoas da associação diminuiu e muito por conta da falta de companheirismo da comunidade, mas mesmo assim a associação nunca perdeu sua força e conta com a contribuição de todos e todas associados e associadas (BARU).

Em terras Indígenas, a organização de associações e/ou cooperativas não fazem parte da cultura organizativa, mas um enfrentamento constante é a disputa de territórios com os latifúndios para o agronegócio.

Nos dias atuais, embora em todos os municípios fronteiriços encontrem-se propriedades produtivas que operam com sistemas eficazes e modernos, as grandes propriedades pouco produtivas e até sem nenhuma produção econômica ainda persistem, o que gera prejuízos para a economia municipal e interfere, negativamente, nos programas que objetivam atender trabalhadores rurais sem terra $e$ indigenas (grifo dos autores). Desta forma, a estrutura latifundiária contribui fortemente para a ocorrência de conflitos agrários, pondo de um lado aqueles que detêm a terra e pouco ou nada produzem e, do outro, trabalhadores que querem e precisam produzir para sobreviver, mas não têm acesso à terra (HIGA; ANZAI; GATTI, 2017, p.48).

Além disso, esses Programas de apoio à agricultura familiar não contemplam as terras indígenas, principalmente porque não há um dono da terra, ela pertence a comunidade, e a não existência de documentação impede $\mathrm{o}$ acesso às políticas vigentes para a agricultura familiar nesses territórios.

No território indígena Rancho Jacaré, para as atividades de agricultura a comunidade conta com apoio de um trator equipado com grade, niveladora e carreta, a manutenção é feita pela prefeitura do município através da secretaria de agricultura, tem tratorista contratado pela secretaria da agricultura do município, que é um indígena,e este é o que faz a preparação da terra das famílias que vão plantar na época do plantio; a maioria das famílias cultivam mandioca, batata, feijão e milho nas roças; a comunidade não tem nenhuma linha de crédito do governo para financiar agricultura. $\mathrm{O}$ único benefício do governo federal é a bolsa família, e algumas sementes entregue pela Funai. A comunidade não tem apoio técnico na agricultura, tudo é feito conforme os conhecimentos tradicionais para manter as roças limpas e sem pragas (JATOBÁ DO CERRADO).

É importante considerar que as situações de organização e produção diagnosticadas nos assentamentos e terras indígenas estão vinculadas às dimensões de cultura e espaço e se inserem num processo de reprodução social, no qual estão implícitos métodos e técnicas da ciência popular no modo de trabalhar a terra, armazenar e cultivar as sementes, cuidar das criações e da produção do alimento: 


\begin{abstract}
A produção que é desenvolvida na Palmeira está sendo o reflexo dos conhecimentos tradicionais voltado principalmente a produção para subsistência, mas com o passar dos anos surge então uma demanda de escoar a produção para obter fins lucrativos para a renda familiar e local (ARAÇÃ).

Sobre o modo de armazenamento das sementes "nos indígenas já praticava este método há muito tempo. As famílias já praticavam esta atividade. $\mathrm{O}$ arroz se guardava na tuia ou lã mesmo na roca, era feito todo um procedimento, e então se ajuntava em cima de um varão de madeira e se criavam. A PIA, era o local que o arroz permanecia por um período até que a outra safra chegasse. A semente era tirada dali. O feijão era também guardado em um local apropriado e dela se tirava a semente e para o consumo, tudo com métodos tradicionais, só quem viveu sabe deste processo. O milho: nas casas existiam as cozinhas separada das casas a onde as famílias dormiam. E lá na cozinha eram condicionadas as sementes de milho. Neste local permanecia a semente para o próximo plantio. Da mesma forma o amendoim. Era guardado em um local dentro de um paiol, de capim (no caso o sape), guardava só a semente que iria plantar no próximo período, no caso o próximo ano (PEQUI).
\end{abstract}

Esses "estilos de agriculturas" tem um "modo particular de combinar, utilizar e desenvolver os recursos agrícolas; é um modo particular de padronizar (no nível micro) os mundos social e material, de forma coerente e autossustentável” (PLOEG, 2011). Reconhecer a existência dessas adjacências é fundamental para compreender as interrelações entre os contextos sociais, econômicos, políticos e culturais, e de como a realidade se expressa a partir desses contextos.

\title{
3.3. Entre a sociologia e as ciências do ter, fazer e re-produzir
}

O acesso aos recursos hídricos é um dos grandes contrastes diante da valorosa presença do Sistema Aquífero Guarani no estado e a contínua escassez de água vivenciada nas comunidades indígenas e rurais locais. A presença de reservas hídricas (nascentes, riachos, rios) são escassas, e as que existem estão em sua maioria desprotegidas de matas ciliares. As que persistem, têm sofrido constantes ataques pela ação antrópica associada aos desmatamentos, queimadas das áreas nativas e demasiado uso de agrotóxicos nas extensas áreas de monocultura. E as questões em torno do acesso a água devem ser consideradas para além do discurso de escassez e serem pensados no que tange aos usos práticos e significados culturais, como propõe Martins (2013):

...além da compreensão histórica dos processos de uso e apropriação dos recursos ecossistêmicos, também faz-se necessária a análise da transformação social da natureza através de um dado território, com formação histórica específica e relações próprias de dominação (p.124). Interpretar a complexidade das esferas de sociabilidade historicamente inscritas nos modos de interação da sociedade com a natureza, permite a construção de 
cenários mais condizentes com o cotidiano dos grupos e classes que possuem interesses concretamente situados diante das potencialidades ecológicas e sociais (p.125).

A produção de resíduos sólidos aumentou demasiadamente com o consumo de alimentos industrializados e de aparelhos eletrônicos. A incineração continua sendo uma das práticas mais comuns no descarte dos resíduos sólidos pela falta de coleta pública nos territórios camponeses e indígenas.

Em relação aos resíduos orgânicos, a prática mais comum é a da compostagem. Mas a maior preocupação está no descarte de embalagens de produtos agroquímicos nos Assentamentos. A maioria dos participantes assentados afirmou a utilização de algum tipo de agrotóxico (ex. Barrage- inseticida de uso veterinário; Gramoxone- herbicida e Baygon- inseticida de uso doméstico), mas ainda há um longo caminho para a sensibilização sobre os usos dessas substâncias e sobre o descarte adequado das embalagens, visto que Barrage e Gramoxone são considerados tóxicos ao meio ambiente e a saúde humana, sendo obrigatória a devolução das embalagens vazias aos distribuidores.

A atual legislação brasileira, que legalizou uma quantidade substancial de agroquímicos para a produção agrícola, bem como as práticas apontadas por parte de alguns agricultores assentados vai na contramão do que está previsto no Objetivo de Desenvolvimento Sustentável (ODS) 3-3.9 "reduzir substancialmente o número de mortes e doenças por produtos químicos perigosos, contaminação e poluição do ar e água do solo" (UNDP, 2016, p. 19) e o ODS 6-6.3 "melhorar a qualidade da água, reduzindo a poluição, eliminando despejo e minimizando a liberação de produtos químicos e materiais perigosos, reduzindo à metade a proporção de águas residuais não tratadas e aumentando substancialmente a reciclagem e reutilização segura globalmente" (UNDP, 2016, p. 21).

Dentre as maiores dificuldades destacadas quanto ao assentamento/aldeia que interferem na qualidade de vida, foram elencadas: Presença de agrotóxicos/poluição; Falta de recursos; Infraestrutura (estradas); Acesso à Saúde; Monoculturas; Insegurança; Falta de união da comunidade. Essa realidade representa o desencontro com o Objetivo de Desenvolvimento Sustentável 15 que é o de "Proteger, recuperar e promover o uso sustentável dos ecossistemas terrestres, gerir de forma sustentável as florestas, combater 
a desertificação, deter e reverter a degradação da terra e deter a perda de biodiversidade" (ODS, 15) (UNDP, 2016 p. 29).

Mas apesar das mazelas, há muitas potencialidades na vida campesina que contribuem para a qualidade de vida nos assentamentos/terras indígenas. Dentre essas estão aspectos relacionados à presença dos recursos naturais (trilhas agroecológicas, cachoeiras; rios e matas; água, alimentos naturais e agroecológicos, ar puro e natureza; contato com a natureza.) e da relação com a comunidade (paz, tranquilidade, sossego, do baixo índice de criminalidade, união, práticas agroecológicas).

Aos conhecimentos traduzidos na vida dos camponeses e indígenas há uma ecologia dos saberes que se materializa "na exploração de práticas científicas alternativas e, por outro lado, da valorização da interdependência dos saberes científicos e não científicos" (DE SOUZA SANTOS, 2018, p. 247).

Distinguir e compreender a realidade do "outro" é fundamental para que o processo de construção do conhecimento se concretize e a socialização desse conhecimento sensibilize para as mudanças necessárias. Como expõe (DE SOUZA SANTOS, 2018),

Não temos acesso direto à realidade porque realmente não a conhecemos mais do que através de conceitos, de teorias, de valores e da linguagem que empregamos. Mas, por outro lado, o conhecimento que construímos sobre a realidade intervém nela e tem suas consequências. $\mathrm{O}$ conhecimento não é representação, é intervenção (p. 247).

A partir dessa contextualização macro, a pesquisa evidenciou uma dimensão teórica importante na formação de professores no ensino de ciências, que é a necessidade de perceber a interrelação entre os saberes e as áreas de conhecimento, isso porque o processo de ensino está profundamente vinculado ao concreto da vida e das transformações ambientais que envolvem esse multiterritório. É nessa perspectiva, inclusive, que Leff (2002, p. 109) salienta que "as mudanças ambientais globais revolucionaram os métodos de pesquisa e as teorias científicas para poder apreender uma realidade em vias de complexização que ultrapassa a capacidade de compreensão e explicação dos paradigmas teóricos estabelecidos".

Tem-se, portanto, que o ensino de ciências se constrói na perspectiva de se relacionar saberes e conhecimentos -visto que a interdisciplinaridade é algo desejável na 
formação de professores da educação do campo-, e também por meio de um real conhecimento do território como espaço de ensino, para além da sala de aula.

Assim, partindo de uma reflexão presente em Latour (2000), essa pesquisa exercita uma análise interdisciplinar no ensino de ciências, posto que a educação do campo tem como perspectiva um olhar transversal sobre os problemas que se apresentam no contexto das escolas do campo.

E reafirma o proposto por Varón Arciniegas et al. (2020), em que:

(...) não é possível educar partindo de uma história em branco; se não se conhece a realidade vivida por detrás de cada um dos estudantes, é muito difícil contextualizar as problemáticas e entender o pensamento do estudante (p. 492). Essas realidades além disso são singulares, já que se parte do fato de que cada ser humano é único e pela mesma razão conta com uma história de vida individual, que é assumida desde seu conhecimento e suas capacidades de resposta frente à sociedade (p. 493).

\section{CONSIDERAÇÕES FINAIS}

Este artigo buscou fazer uma relação da interface entre o ensino de ciências e a sociologia ambiental na formação de professores, apontando para a necessidade que há de se partir de uma perspectiva de ciência interdisciplinar entre as ciências humanas e as ciências da natureza, tendo em vista que a vida concreta dos estudantes em seus mais diversos territórios, não é compartimentado, antes está interligado a uma multiplicidade de fatores.

Em relação às políticas públicas para à agricultura familiar, uma pequena parcela de camponeses tem conseguido acessar os programas, por falta de regulamentação dos lotes, burocracias nas instituições e agências bancárias e a falta de informações junto às famílias assentadas. A situação ainda é mais crítica em relação aos povos guarani kaiowá sendo urgente o estabelecimento de políticas públicas específicas, que garantam a proteção das áreas indígenas bem como da continuidade das práticas tradicionais em consonância com os seus territórios e culturas.

Ressaltamos ainda que a especificidade da formação de professores da educação do campo, pressupõe um profundo conhecimento do território escolar em que está situado, reivindicando uma educação transformadora e vinculada às especificidades do lugar. Isso porque, de fato, o território indígena e camponês, como visto nas normativas 
da educação do campo, também é constitutivo de saberes e da (re)produção de conteúdos simbólicos, culturais, ambientais e tradicionais.

\section{REFERÊNCIAS}

AQUINO, J. R.; SCHNEIDER, S. de. O Pronaf e o desenvolvimento rural brasileiro: avanços, contradições e desafios para o futuro. In: GRISA, C.; SCHNEIDER, S. (Org.) Políticas públicas de desenvolvimento rural no Brasil, Porto Alegre: Editora da UFRGS, 2015. p. 53-81.

BRASIL. Ministério da Educação. Secretaria de Educação Continuada, Alfabetização, Diversidade e Inclusão - SECADI. Educação do Campo: marcos normativos/Secretaria de Educação Continuada, Alfabetização, Diversidade e Inclusão - Brasília: SECADI, 2012a. 96 p. Disponível em:

http://pronacampo.mec.gov.br/images/pdf/bib_educ_campo.pdf. Acesso em: 01 set. 2020 .

BRASIL. Ministério da Educação. Conselho Nacional de Educação. Resolução $\mathbf{N}^{\mathbf{0}} \mathbf{2}$, de 15 de junho de 2012: Estabelece as Diretrizes Curriculares Nacionais para a Educação Ambiental. 2012b. Disponível em:

http://portal.mec.gov.br/dmdocuments/rcp002_12.pdf. Acesso em: 01 set. 2020.

BRASIL. Ministério da Integração Nacional. Secretaria de Programas Regionais. Programa de Desenvolvimento da Faixa de Fronteira. Proposta de Reestruturação do Programa de Desenvolvimento da Faixa de Fronteira/Ministério da Integração Nacional, Secretaria de Programas Regionais, Programa de Desenvolvimento da Faixa de Fronteira - Brasília: Ministério da Integração Nacional, 2005. Disponível em: https://www.paho.org/bra/index.php?option=com_docman\&view=download\&alias $=697$ -proposta-reestruturacao-do-programa-desenvolvimento-da-faixa-fronteira7\&category_slug=mercosul-162\&Itemid=965. Acesso em: 01 set. 2020.

BRASIL. Ministério da Agricultura e do Abastecimento. PRONAF - Programa Nacional de Fortalecimento da Agricultura Familiar. Brasília, maio de 1996. Disponível em: https://www2.camara.leg.br/legin/fed/decret/1996/decreto-1946-28-junho-1996435815-publicacaooriginal-1-pe.html. Acesso em: 01 set. 2020.

BOURDIEU, P.; PASSERON, J.-C. A reprodução: Elementos para uma teoria do sistema de ensino. 7. ed. Petrópolis, RJ: Vozes, 2014.

CALDART, R. S. (Org.). Dicionário da Educação do Campo. Rio de Janeiro, São Paulo: Escola Politécnica de Saúde Joaquim Venâncio, Expressão Popular, 2012.

CALDART, R. S. Pensando a educação dos camponeses. In: WIZNIEWSKY, C.R.F.; MOURAD, L. A. de F. A. (Org.). Educação, memória e resistência popular na formação social da América Latina. Porto Alegre: Evangraf, 2016. 
CHAMORRO, G.; COMBÈS, I. Introdução. In: CHAMORRO, G.; COMBÈS, I. (Org.).

Povos indígenas em Mato Grosso do Sul: história, cultura e transformações sociais.

Dourados, MS: Ed. UFGD, p. 19-24, 2015. E-book. Disponível em:

http://files.ufgd.edu.br/arquivos/arquivos/78/EDITORA/catalogo/povos_indigenas_em_ mato_grosso_do_sul.pdf._Acesso em: 18 maio 2020.

DE SOUSA SANTOS, B. Construindo as Epistemologias do Sul: Antologia Essencial. Volume I: Para um pensamento alternativo de alternativas / Boaventura de Sousa Santos; compilado por Maria Paula Meneses... [et al.]. - 1.ed. - Ciudad Autónoma de Buenos Aires: CLACSO, 2018. v. 1, 688p. E-book. Disponível em: http://www.boaventuradesousasantos.pt/media/Antologia_Boaventura_PT1.pdf. Acesso em: 02 set. 2020.

FARINACCIO, M. A. et al. A flora no Biota-MS: montando o quebra-cabeça da biodiversidade de Mato Grosso do Sul. Iheringia, Série Botânica, Porto Alegre, 73 (supl.), p. 11-17, 2018. Disponível em: file://C:/Users/Usuario/Downloads/675-2550-2PB.pdf. Acesso em: 04 set. 2020.

GRACIOLLI, G. et al. Biota-MS: Montando o quebra-cabeça da biodiversidade de Mato Grosso do Sul. Iheringia, Série Zoologia, Porto Alegre, 107 (supl.): e2017100, 2017. Disponível em: https:/www.scielo.br/pdf/isz/v107s0/1678-4766-isz-107e2017100.pdf. Acesso em: 04 set. 2020.

GRISA, C.; PORTO, S. I. Dez anos de PAA: as contribuições e os desafios para o desenvolvimento rural. In: GRISA, C.; SCHNEIDER, S. (Org.). Políticas públicas de desenvolvimento rural no Brasil. Porto Alegre: Editora da UFRGS, 2015, p. 155-180.

GRISA, C.; SCHNEIDER, S. Três gerações de políticas públicas para a agricultura familiar e formas de interação entre sociedade e Estado no Brasil. In: GRISA, C.; SCHNEIDER, S. (Org.). Políticas públicas de desenvolvimento rural no Brasil. Porto Alegre: Editora da UFRGS, 2015, p. 19-50.

HEBERLÊ, A. L. O. et al. Agricultura familiar e pesquisa agropecuária: contribuições para uma agenda de futuro. In: DELGADO, G. C.; BERGAMASCO, S. M. P. P. (Org.). Agricultura familiar brasileira: desafios e perspectivas de futuro. Brasília: Ministério do Desenvolvimento Agrário, 2017. p. 131-148. E-book. Disponível em: https://www.cfn.org.br/wp-content/uploads/2017/10/Agricultura_Familiar.pdf. Acesso em: 22 ago. 2020.

HIGA, T. C. C. de S.; ANZAI, L. C.; GATTI, F. Formação da estrutura agrária produtiva dos Municípios da fronteira oeste brasileira com a Bolívia. In: PENHA, Bruna; NETO, W. A. D.; MORAES, R. F. de. (Org.). O Mercosul e as regiões de fronteira. Rio de Janeiro: Ipea, 2017. p. 13-52. E-book. Disponível em: https://www.ipea.gov.br/portal/images/stories/PDFs/livros/livros/171101_livro_mercos ul.pdf. Acesso em: 30 ago. 2020.

IBGE - Instituto Brasileiro de Geografia e Estatística. Perfil dos municípios brasileiros 2013. Rio de Janeiro: 2014, 282p. E-book. Disponível em: file://C:/Users/Usuario/Downloads/munic2013.pdf. Acesso em: 04 set. 2020. 
INCRA. Instituto Nacional de Colonização e Reforma Agrária. Painel dos assentamentos - Mato Grosso do Sul - SR16. Disponível em:

http://painel.incra.gov.br/sistemas/index.php. Acesso em 09 set. 2020.

LATOUR, B. Ciência em ação: como seguir cientistas e engenheiros sociedade afora. São Paulo, UNESP, 2000.

LEFF, E. Epistemologia ambiental. 5. ed. São Paulo: Cortez, 2002.

MARTINS, R. C.; MADUREIRA, G. A. Do "buraco" ao atrativo turístico: uma sociologia da ressignificação do rural. Revista de Economia e Sociologia Rural, Brasília, v. 57, n. 2, p. 326-338, 2019. Disponível em: https://doi.org/10.1590/18069479.2019.185693. Acesso em: 04 set. 2020.

MARTINS, R. C. A construção social da economia política da água. Sociologia, Problemas e Práticas, Lisboa, n. 73, p. 111-130, 2013. Disponível em:

https://revistas.rcaap.pt/sociologiapp/article/view/2810/2370. Acesso em: 04 set. 2020.

MARTINS, R. C.; CUNHA, L. H. Ruralidades e meio ambiente: a constituição de um campo de investigação na sociologia. BIB, São Paulo, n. 92, 2020 (publicada em abril de 2020), p. 1-29. Disponível em:

http://anpocs.com/images/BIB/n92/BIB_0009204_RP_rodrigo_luis.pdf. Acesso em: 07 set. 2020.

MDA- Ministério do Desenvolvimento Agrário. Plano Safra da Agricultura Familiar 2012/2013. 2013. 19p. Disponível em:

https://cms20.simplesnologia.biz/Arquivos/Empresa_020CONTEUDO_00000043_Ane xos/Original/020000000430021_0.pdf. Acesso em: 22 ago. 2020

MOLINA, M. C. Ministério do Desenvolvimento Agrário. Educação do Campo e Pesquisa: questões para reflexão. - Brasília: Ministério do Desenvolvimento Agrário, 2006. $152 \mathrm{p}$.

NETO, W. A. D.; PENHA, B. As regiões de fronteira como laboratório da integração regional no Mercosul. In: PENHA, B.; NETO, W. A. D.; MORAES, R. F. de. (Org.). O Mercosul e as regiões de fronteira. Rio de Janeiro: Ipea, 2017. p. 203-225. E-book. Disponível em:

https://www.ipea.gov.br/portal/images/stories/PDFs/livros/livros/171101_livro_mercos ul.pdf. Acesso em: 30 ago. 2020.

PLOEG, J. D. V. D. Trajetórias do desenvolvimento rural: pesquisa comparativa internacional. Sociologias, Porto Alegre, v. 13, n. 27, p. 114-140, 2011. Disponível em: https://www.scielo.br/pdf/soc/v13n27/a06v13n27.pdf. Acesso em: 04 set. 2020.

ROCHA, N. C. A segurança alimentar e nutricional e o direito humano à alimentação adequada. In: LEÃO, M. (Org.). O direito humano à alimentação adequada e o sistema nacional de segurança alimentar e nutricional. Brasília: ABRANDH, 2013. p.10-42. E-book. Disponível em: 
http://www.mds.gov.br/webarquivos/publicacao/seguranca_alimentar/DHAA_SAN.pdf. Acesso em: 04 set. 2020.

SABOURIN, E.; SAMPER, M.; MASSARDIER, G. Políticas públicas para as agriculturas familiares: existe um modelo latino- americano? In: GRISA, C.; SCHNEIDER, S. (Org.). Políticas públicas de desenvolvimento rural no Brasil. Porto Alegre: Editora da UFRGS, 2015, p. 595-616.

SANTA CRUZ, J. N.; et al., Síntese Hidrogeológica do Sistema Aquífero Guarani. Projeto para a Proteção Ambiental e Desenvolvimento Sustentável do Sistema Aquífero Guarani, 2009. Disponível em: file://C:/Users/Usuario/Downloads/sag_sintese.pdf. Acesso em: 27 ago. 2020.

SECID/MS- Subsecretaria Especial da Cidadania. Comunidades Indígenas. 2020. Disponível em: https://www.secid.ms.gov.br/comunidades-indigenas-2/. Acesso em: 27 ago. 2020.

UNDP- United Nations Development Programme. AGENDA 2030. Traduzido do inglês pelo Centro de Informação das Nações Unidas para o Brasil (UNIC Rio) e revisado pela 42 Coordenadoria-Geral de Desenvolvimento Sustentável (CGDES) do Ministério das Relações Exteriores do Brasil. Última edição em 11 de fevereiro de 2016. Disponível em: https://www.undp.org/content/dam/brazil/docs/agenda2030/undpbr-Agenda2030-completo-pt-br-2016.pdf. Acesso em: 01 set. 2020.

VARÓN ARCINIEGAS, V. et al. Pedagogía de la alteridad: entre la educación como práctica social y el ejercicio intelectual. Revista Insignare Scientia, Cerro Largo, v. 3, n. 2, p. 484-508, 2020. Disponível em: https://doi.org/10.36661/2595-

$4520.2020 \mathrm{v} 3 \mathrm{i} 2.11582$ 